\title{
La izquierda en las transiciones a la democracia. El caso uruguayo
}

\author{
Eugenia Allier Montaño*
}

\section{Resumen}

En este artículo se lleva a cabo un seguimiento histórico-político de la actuación del Frente Amplio en la transición a la democracia en Uruguay. Si bien este proceso ocurrió de 1980 a 1989 , en este artículo sólo se analiza el papel del Frente de 1980 a 1984 , periodo en el cual los militares todavía estaban en el gobierno. Fue entonces cuando el papel del Frente sería determinante en el proceso general, además de ser cuando consolidaría su papel como actor imprescindible en la escena política uruguaya. Se pueden ubicar tres momentos fundamentales de su actuación en esa etapa: 1) su participación en las elecciones internas de los partidos tradicionales en 1982 ; 2) su fortalecimiento en 1983 , y 3) su participación en la salida pactada del gobierno de la dictadura en 1984 .

\section{Abstract}

In this article we perform a follow up of the Broad Front as an actor through the democratic transition in Uruguay. Although this process took place from 1980 to 1989 , only the period covering up to 1984 is analyzed. This is a specially important time frame, given that the military was still on hold of the power. It was then that the Broad Front' paper became a key point in the overall process and its consolidation as a major political actor in the uruguayan political arena was established. Three fundamental facts can be identified as the Broad Front's participation in this stage: 1 ) Its appearance in the traditional parties' internal elections in $1982 ; 2$ ) Its strengthening in 1983 , and 3) Its role in the negotiated leaving of the military dictatorship in 1984 .
Palabras clave:

Uruguay, transición, democracia, militares, partidos políticos, izquierda.
Fecha de recepción: mayo de 1998

Fecha de aceptación: abril de 2000

* Doctorante en Historia y civilización, École des Hautes Études en Sciences Sociales (Francia), 1999-2001. Correo electrónico: eallier69@hotmail.com 
$\mathrm{E}$ n los últimos años, el estudio de las transiciones a la democracia ha ocupado un espacio importante entre los politólogos, historiadores y economistas. Éstas han sido muy polémicas en todos los ámbitos y, también, muy diversas en su composición y desarrollo. De ellas se ha estudiado el inicio, el fin y el porqué de cada uno de estos procesos así como el comportamiento de los actores políticos que participaron en las mismas. Es evidente que en cada nación la transición se ha distinguido por elementos propios y únicos que no aparecen en otras. Sin embargo, el análisis de estos casos es importante para poder elaborar una teoría general sobre las transiciones a la democracia.

Además, la izquierda pocas veces ha sido el centro de estos estudios. La propuesta aquí es revisar en un caso nacional el papel de la izquierda en la transición a la democracia, concretamente en Uruguay. Se considera que tal propuesta se justifica, ya que la izquierda ha sido marginada como actor político en el análisis de las transiciọnes $y$, por tanto, como un elemento particular en las mismas.

Antes de comenzar habría que exponer dos puntos. Primero, que la izquierda uruguaya analizada será el Frente Amplio (FA), por ser una coalición de partidos y organizaciones de izquierda, surgido en 1971, tras la convocatoria para crear un frente opositor de izquierda. Segundo, que se entiende por transición el intervalo transcurrido entre un régimen político y otro, y delimitado por el inicio de la disolución del régimen autoritario y por la resolución de todos los conflictos existentes entre ambas partes: en este caso militares y civiles -representados por los políticos-,es decir, cuando los asuntos pendientes del régimen anterior son finiquitados. Lo característico de las transiciones es que las reglas del juego político no están definidas: las reglas emergentes determinarán a los actores del mismo. ${ }^{1}$

Sin embargo, debo aclarar que en este artículo no se abarcará la transición completa, que en el caso de Uruguay va de 1980 a 1989 , pues se considera mucho más relevante la participación del Fa en la primera parte de la misma (19801984, todavía durante el gobierno militar), dado que es ahí donde éste consolidaría su papel como actor imprescindible en la arena política uruguaya.

Antes de entrar de lleno en el tema, es necesario recordar algunas cuestiones históricas acerca de Uruguay, para hacer entendible la transición a la de. mocracia de los años ochenta.

\section{ANTECEDENTES HISTÓRICOS}

En Uruguay se instaura, desde los primeros años del siglo $\mathrm{XX}$, un sistema partidario de tipo representativo, donde los partidos desempeñan un papel fundamental. La estabilidad partidaria se logró durante los gobiernos de José Batlle y Ordóñez, debido a que, a principios de siglo, se dio el desarrollo de los sectores vinculados al comercio y la industria; finalizaron las guerras civiles; se amplió la legislación laboral, y se facilitó el desarrollo del llamado "Estado benefactor".

\footnotetext{
${ }^{1}$ Ver O'Donnell, Transiciones, 1988, t. 4
} 
El sistema de partidos se consolidaría con una base bipartidista compuesta por el Partido Nacional y el Partido Colorado, base que no obstante tendía al pluralismo, ya que aceptaría la existencia del Partido Comunista y el Socialista. Aquí cabría aclarar que entre los plantamientos del Partido Nacional (PN) y el Partido Colorado (PC) no hay grandes diferencias, aunque en sus orígenes el Nacional era más rural, y el Colorado más urbano. Sin embargo, esas diferencias de extracción fueron diluyéndose con el tiempo y sólo quedaron diferencias emotivas por parte del electorado. Los dos partidos políticos son además multiclasistas y multiideológicos, aunque ambos tienden al anticomunismo. Hay mayores diferencias en su interior, como partidos tradicionales, que entre ellos dos. Esto podía darse debido a la existencia de la Ley de Lemas, la cual determinaba que, dentro de cada partido político denominado lema, existiera una fraccionalización en corrientes o grupos, llamados sublemas. Cada sublema tenía derecho a postular candidatos, tanto a la presidencia como a otros cargos de elección popular; de forma tal, que cada partido o lema podía llegar a presentar tres o más candidatos a la presidencia. La legislación permitía, en ese sentido, que todos los votos de los sublemas se sumaran al lema. Por tanto, al emitir su voto el ciudadano lo hacía por el sublema y por el lema; este procedimiento se tradujo en el doble voto simultáneo, resultante de la Ley de Lemas. ${ }^{2}$

${ }^{2}$ Cabe aclarar que esta ley dejó de tener vigencia con la reforma electoral llevada a cabo
En consecuencia, por lo menos desde la mitad del siglo XIX y hasta 1971, en que surgió el Frente Amplio, existió en Uruguay un sistema prácticamente bipartidista; aunque es necesario mencionar a la Unión Cívica ${ }^{3}$ que, en general, ha representado una insignificante manifestación de la sociedad uruguaya, pero que, no obstante, ha servido para establecer pactos y acuerdos entre las fuerzas mayoritarias en momentos de inestabilidad.

Hasta la década de los cincuenta, Uruguay había visto crecer su industria y fortalecerse su economía. Posteriormente, la crisis nacional, combinada con la internacional, comenzó a producir los primeros desajustes económicos. Con la crisis económica las tensiones sociales crecieron, iniciándose las protestas de los sectores asalariados y de los pequeños y medianos empresarios. La inadecuación creciente de los canales tradicionales de representación política y las expresiones cada vez más continuas de protesta y organización de los sectores asalariados, fueron acompañadas de un mayor endurecimiento represivo por parte del gobierno.

En ese contexto surgió el Movimiento de Liberación Nacional, Tupamaros, planteando una ruptura con el sistema político y apareciendo como guerrilla urbana, lo cual rompía con todos los métodos de lucha social que habían imperado en el país durante el siglo XX.

antes de las elecciones del año 1999, en las cuales, por primera vez en Uruguay, cada partido presentó un solo candidato a la elección presidencial.

${ }^{3}$ La Unión Cívica es un pequeño partido de ideología cristiano-conservadora fundado a principios de siglo. 

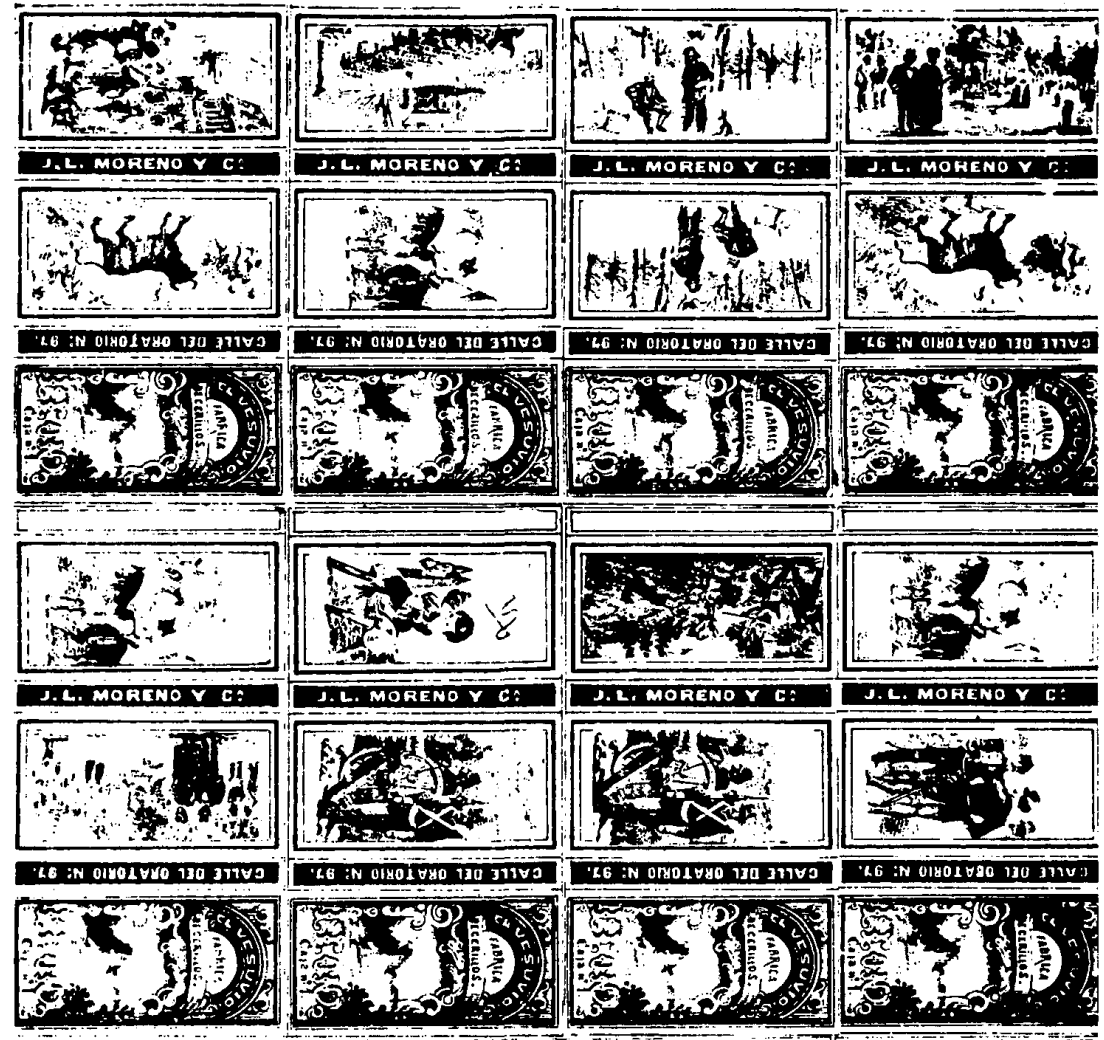

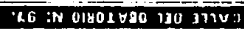
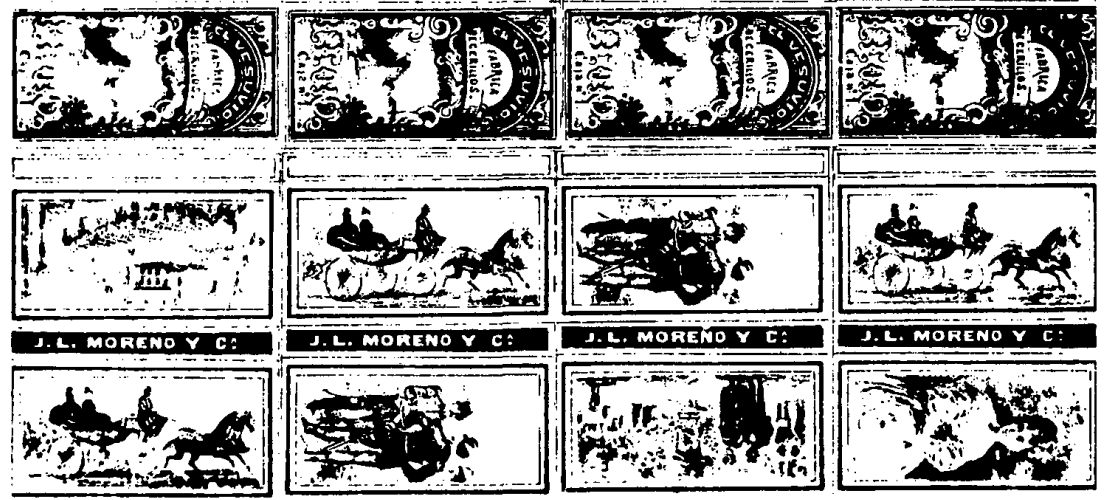
En las elecciones de 1966 tomaría el poder el general Óscar Gestido, del Partido Colorado, que falleció antes de concluir su mandato, y en 1967 asumió la presidencia Jorge Pacheco Areco, director del diario colorado El Día. Con él, el gobierno se volvió más autoritario y la política social más rígida. Por ello su gobierno es conocido coloquialmente como la dictadura constitucional o la primera fase del estado de excepción.

En esa misma época comenzaron a darse los primeros acercamientos para formar un frente político de izquierda, cuyos orígenes fueron la creación de la Confederación Nacional de Trabajadores (CNT) y del Frente Izquierda de Liberación (FIDEL). El 7 de octubre de 1970 se lanzó la convocatoria para formar el Frente Amplio y, así, en 1971, se conformó la coalición de izquierda.

Al mismo tiempo que las Fuerzas Armadas (FFAA) iban acrecentando su poder como conductores de la lucha antisubversiva, comenzaron a tener injerencia en la política por dos razones: primero, porque a ellos mismos les iba surgiendo una concepción más política de su actuación, y segundo, porque el presidente de la república y los políticos así se lo pidieron.

En 1971, bajo la presidencia de Bordaberry, proveniente de la oligarquía terrateniente, se comenzaría a considerar la aplicación de la Doctrina de Seguridad Nacional (DSN) en Uruguay, cuyos antecedentes se encuentran en: a) el ejército colonial francés; $b$ ) las doctrinas de la España franquista; $c$ ) la nueva concepción de Estados Unidos de los militares latinoamericanos y $d$ ) las directrices de la Escuela Superior de Guerra de Brasil.
Los puntos fundamentales de la DSN son: la guerra contra el comunismo y la subversión, considerando que el capitalismo está indefenso frente a ellos y que las FFAA son las llamadas a protegerlo. La política, entendida como estrategia militar, deja de ser una actividad autónoma con reglas y objetivos propios, para transformarse en una valoración estratégica donde las acciones y los objetivos se miden de acuerdo con la lógica de la guerra. Las FFAA justifican su presencia en la vida política del país a través de la seguridad y el desarrollo de la nación, lo cual es el producto de la conjunción del pueblo, el gobierno y el ejército. ${ }^{4}$

Si bien desde 1971 los militares comenzaron a tener un gran protagonismo en la vida política uruguaya, no fue sino hasta 1973 que entraron de lleno en ella. En febrero de ese año exigieron a Bordaberry una mayor participación en la conducción del país. El presidente se vio obligado a negociar con ellos, pues no contaba con ningún apoyo de la sociedad civil ni de los partidos. Así, se llegó al "Acuerdo de Boissso Lanza", en el cual se convino la creación del Consejo de Seguridad Nacional (COSENA). ${ }^{5}$

El 27 de junio de 1973, el presidente de la república proclamó el golpe de Estado y el ejército ocupó el Palacio Legislativo, comenzando así la dictadura comisarial. Entre las primeras

\footnotetext{
${ }^{4}$ Para ampliar la información sobre la DSN, ver Castagnola y Mieres, Ideología, 1989.

${ }^{5}$ El COSENA estaba integrado directamente por los mandos militares. Al formarlo, se le concedió la participación orgánica en la conducción estatal del gobierno.
} 
medidas que tomó entonces Bordaberry estuvo la disolución de la CNT, misma que agrupaba a la oposición en contra de las medidas autoritarias, aunada al FA y a algunos sectores del PN.

Frente al golpe, la CNT declaró la huelga general, que prosiguió por espacio de quince días y que fue considerablemente apoyada por el Frente Amplio y el Partido Nacional. El 9 de julio se realizó una enorme manifestación en contra del gobierno. Ahí fue apresado y encarcelado Líber Seregni, líder de la coalición de izquierda, quien fue liberado en 1975 y vuelto a encarcelar en 1976. La represión fue, en esos años, la característica general del nuevo gobierno: contra la universidad, los sindicatos, el FA y sus partidos políticos, la Federación de Estudiantes Universitarios de Uruguay -FEUU- y algunas revistas a través de su clausura, como en el caso de Marcha, siendo apresados Carlos Quijano, Juan Carlos Onetti y Hugo Alfaro, entre otros. Los partidos, mientras tanto, parecían hibernar constriñendo su acción dado el recrudecimiento de la represión.

En 1976 comenzaron a surgir diferencias entre los distintos sectores de las FFAA y, a consecuencia de ello, fue removido Bordaberry e impuesto como presidente Alberto Demicheli el 12 de junio; como éste se negó a firmar la proscripción de los partidos y grupos políticos, fue también removido del puesto, el primero de septiembre.

La represión militar no podía mantenerse sin que el ejército dispusiera de un proyecto político más amplio. En ese contexto Aparicio Méndez, miembro del Consejo de Estado, asumió la presidencia de la república. El mismo día que éste llegó al poder, los militares dictaron el Acto Institucional núm. 4-AI4-, por el cual, se declaraba proscritos a los ciudadanos que hubiesen sido candidatos a cargos nacionales, departamentales o locales en las elecciones de 1966 y 1971; ello significaba que no podían ejercer cargos políticos en los siguientes quince años. Con esa medida, concluía la dictadura comisarial fundadora del orden autoritario militar (1973-1976). ${ }^{6}$

El 9 de agosto de 1977, los militares lanzaron un primer cronograma que buscaba institucionalizar el autoritarismo. En él se incluía un plan de depuración de los partidos tradicionales, un plebiscito para elaborar una nueva constitución y una convocatoria a elecciones nacionales con un solo candidato. Este llamamiento inicia la segunda época de la dictadura: es el ensayo fundacional de una nueva república "tutelada" por las Fuerzas Armadas.

Los propósitos de esa nueva constitución que se quería elaborar eran: acabar con la Ley de Lemas y el doble voto simultáneo; la institucionalización del COSENA; el condicionamiento de las huelgas; la modificación de la ley de allanamientos nocturnos, y el establecimiento de la inamovilidad de los funcionarios públicos.

El 30 de noviembre de 1980 se plebiscitó el proyecto. Ganó el NO, que representaba el rechazo a la nueva constitución, con $57.9 \%$ De esa manera, la dictadura sufrió un primer gran revés de parte de la población civil.

\footnotetext{
${ }^{6} \mathrm{La}$ periodización de la dictadura es ampliamente trabajada por Caetano y Rilla, Breve, 1989
} 
Con ello concluía el intento fundacional de la dictadura uruguaya, y se iniciaba la transición a la democracia.

Después de 1980 los militares estaban casi convencidos de que, de seguir solos, debían abandonar el gobierno, únicamente necesitaban definir el cómo. Sabían que no podían mantenerse sin los políticos, por lo cual, entre 1980 y 1981, comenzaron a darse los primeros acercamientos, aunque informales, entre los militares y los políticos tradicionales.

El 28 de julio de 1981, las FFAA aprobaron el AI11, por el que se establecía una transición de tres años para dejar ellas el gobierno; se definía la elección de un nuevo presidente de la república y se ampliaban las competencias del Consejo de Estado. Así, el primero de septiembre asumió como presidente de la república el general Gregorio Álvarez. Ese mismo año empezó a discutirse el nuevo estatuto -o ley- para los partidos políticos y la convocatoria a elecciones a los partidos tradicionales y la Unión Cívica; la izquierda partidaria quedaba aún fuera del proceso, pues como se la seguía considerando un peligro para la sociedad, debía desaparecer.

A partir de ese momento, la participación del FA comenzó a ser importante en el desarrollo de la transición a la democracia. En esa primera parte de la transición pueden ubicarse tres momentos fundamentales de la actuación política del Frente: su participación en las elecciones internas de los partidos tradicionales en 1982, su fortalecimiento en 1983 y su participación en la salida pactada de la dictadura en 1984 . Veamos cada uno de ellos.
1982: ELECCIONES INTERNAS DE

LOS PARTIDOS TRADICIONALES.

"El FRENTE AMPLIO SE ENCUENTRA

EN LA DISYUNTIVA DEL VOTO EN

BLANCO O EL VOTO ÚTIL

El año 1982 constituyó el regreso de los partidos a la escena política. A partir de entonces comenzaron a retomar, aunque con caídas y dificultades, su posición de primer plano en el sistema político.

Tras las primeras conversaciones en 1981, los políticos de los partidos Nacional, Colorado y Unión Cívica demandaron a las FFAA su regreso a la arena política: en primer lugar, participando en la discusión del estatuto de los partidos y en la convocatoria a las elecciones internas de los mismos. El 26 de julio de ese año, el gobierno militar levantó las primeras 100 proscripciones, que incluían a colorados, blancos y cívicos.

Es importante mencionar que desde entonces, el Frente Amplio era considerado completamente fuera de los planes de los militares, de manera que, en 1982, no hubo pláticas entre éstos y los frenteamplistas. Para las FFAA, el Frente continuaba excluido de la posibilidad de reingresar al escenario político, por lo cual la coalición de izquierda no debía tomar parte en las elecciones internas de los partidos. Como veremos más adelante, eso no significa que no hayan tenido un papel activo en las mismas. No obstante, antes de continuar con el análisis de las elecciones internas, es importante dejar claro que los militares no incluyeron al Frente en las negociaciones que mantuvieron con todos los demás partidos, 


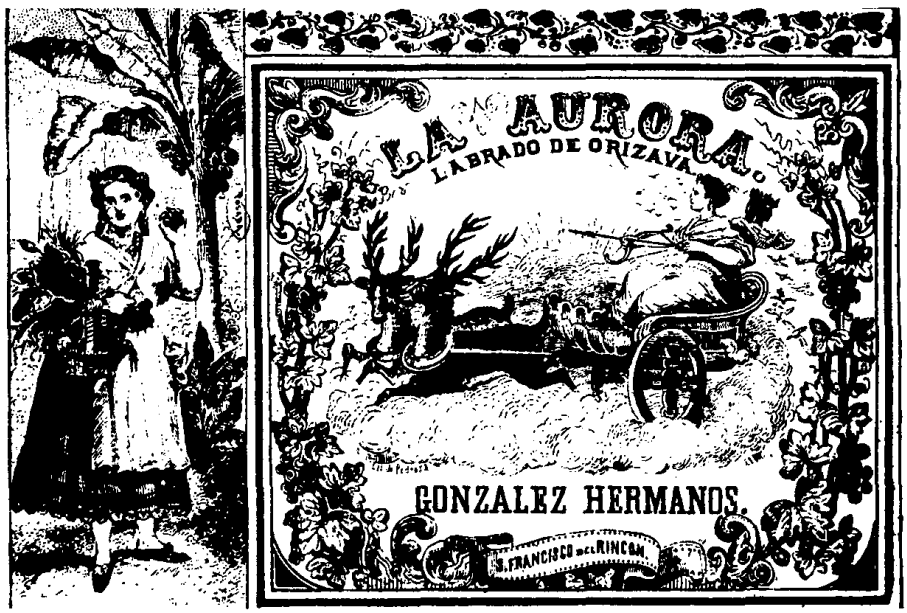

ni en las elecciones internas. Las elecciones internas sólo se establecieron para el Partido Colorado, el Nacional y la Unión Cívica.

Por parte de los militares y políticos, era una forma de acelerar el proceso de las elecciones internas, mismas que seguían el modelo de las elecciones primarias de Estados Unidos: todo ciudadano que fuera parte del padrón electoral podía presentarse y votar por una de las opciones de uno de los partidos. Aparentemente, no era entonces una disputa entre partidos, sino entre los sectores y las tendencias de cada partido, aunque políticamente tenía gran importancia qué partidos y qué sectores recibirían mayor apoyo popular. La ley para los partidos fue hecha conforme a lo que de ella querían los militares. Sin embargo, es importante abundar en que derivó en la reconstitución de los partidos políti- cos, a fin de que éstos pudieran designar a los dirigentes que participarían en el diálogo con los militares, para buscar la salida a la dictadura.

Algunas de las características del estatuto eran: la supresión de la elección directa de dirigentes de las organizaciones históricas -que se haría en segundo grado en las convenciones-; la prohibición de acumular votos por sublemas; la supresión de que un ciudadano pudiera ser candidato a un cargo convencional por más de un departamento; ${ }^{7}$ el requerimiento para postular candidatos a los cargos públicos, de un mínimo de $25 \%$ de la votación del lema o partido; la exigencia de que los futuros integrantes del Directorio y de la Convención hubieran sido previamente electos a cargos de ésta; la

${ }^{7}$ La división política de Uruguay está basada en la figura territorial de los departamentos. 
autorización exclusiva de votar a los ciudadanos no proscritos, mayores de 18 años; la vigencia del AI4, con lo cual muchos dirigentes de los partidos tradicionales no podían ser elegidos, y la prohibición, en las campañas electorales, de tratar algunos temas referidos a la economía, a las proscripciones y los problemas sociales.

No obstante su inconformidad con la metodología, los partidos aceptaron ir a elecciones internas, porque suponían un reto para debilitar a la dictadura: con la Ley Fundamental núm. 2, o Ley de partidos, se reconstruía el sistema de partidos.

Después del plebiscito de 1980 , las elecciones de 1982 constituyeron el segundo y más importante momento de liberalización ${ }^{8}$ y de confrontación con la dictadura.

¿Cuáles fueron las opciones políticas en 1982? Por el Partido Colorado se presentaban tres frentes: 1) la Unión Colorada y Ballista, liderada por Jorge Pacheco Areco, de corte oficialista; 2) los sublemas Unidad y Reforma, y Libertad y Cambio, liderados por Juan María Sanguinetti y Enrique Tarigo, respectivamente y 3) la Corriente Ballista Independiente, liderada por Manuel Flores Silva, como el ala izquierda.

\footnotetext{
${ }^{8}$ Por liberalización entendemos el proceso de redefinición y ampliación de los derechos. En el plano de los grupos, abarca la libertad para expresar colectivamente su discrepancia respecto de la política oficial sin sufrir castigo por ello, inexistencia de censura en los medios y libertad para asociarse con otros ciudadanos para expresarse políticamente. Sin embargo, en una transición estas garantías nunca son respetadas de manera total por las autoridades y su contenido es modificado a través del tiempo.
}

El Partido Nacional también presentaba tres frentes: 1) Adelante con $\mathrm{Fe}$ -ACF-, liderado por Wilson Ferreira Aldunate, aunque desde el exterior, era opositor a la dictadura -aquí se incluía el grupo Convergencia Democrática; ${ }^{9}$ 2) el Consejo Nacional Herrerista, liderado por Luis Alberto Lacalle y 3) el sector oficialista, representado por pequeños sectores del herrerismo, bajo el sublema Libertad y Servicio, liderado por Alberto Gallinal.

A pesar de que las elecciones no fueron obligatorias, votó $60.5 \%$ de los habilitados. Los resultados fueron los siguientes: Partido Nacional: 619 945; Partido Colorado: 527 562; Unión Cívica: 14986 y voto en blanco: 85373 . Dentro de la votación del Partido Nacional, $81 \%$ apoyó a los sectores que reconocían, por encima de sus líderes, a Wilson Ferreira Aldunate. En el Partido Colorado, $69 \%$ apoyó a Julio Ma. Sanguinetti y Enrique Tarigo. ${ }^{10}$

De esta forma comenzaría a darse la liberalización, con la posibilidad de que los ciudadanos expresaran sus preferencias políticas. Sin embargo, en las transiciones la represión es la contraparte de la liberalización, y 1982 estuvo signado por esta ambivalencia.

En el caso uruguayo nunca dejó de existir, durante el periodo estudiado, la censura sobre los medios de comu-

${ }^{9}$ Convergencia Democrática de Uruguay (CDU) fue una organización que se conformó en México y que agrupaba a diversos políticos y militantes, básicamente blancos, comunistas y socialistas, exiliados en este país. Se unían como un polo de oposición a la dictadura. Ver Convergencia, 1984.

${ }^{10}$ Tomado de Zubillaga, "Partidos", 1991, pp. 104-105. 
nicación. Y particularmente en el caso de las elecciones de 1982 se advierte que no hubo libertad total para expresar colectivamente la discrepancia con respecto de la política oficial, ni siquiera en los partidos habilitados. Entonces, la liberalización, sería un proceso mediante el cual las FFAA permitieron a ciertos ciudadanos algunas libertades políticas, excluyendo de ellas a los frenteamplistas.

A partir de 1980 comenzaron a surgir periódicos y semanarios de oposición, entre los que resaltan: Opinar -colorado-, Opción -demócratacristiano-, La Democracia -blanco-, Correo de los Viernes -colorado- y Jaque -colorado.

A principios de 1982 fueron clausurados, por ocho números, La Democracia y Opinar, en tanto la revista $L a$ Plaza -comunista- era clausurada definitivamente. Estas clausuras se debieron, principalmente, a la mención de políticos proscritos. Opción también fue clausurada, pero por promover el voto en blanco. Pero los periódicos de oposición, aunque sufrían la represión de los militares, fungieron también como una de las formas del quehacer político que abrió caminos para la libertad de expresión.

La represión afectó incluso a los políticos. Días antes de las elecciones, fueron detenidos varios elementos del Partido Nacional. Asimismo, se detuvo a dirigentes sindicales, acusados de comunistas.

Hasta 1982, el FA había sido el sector político más castigado por los militares, por lo cual los partidos y organizaciones que lo integraban trabajaban en la casi total clandestinidad. An- te esa realidad, y dado que la coalición no podría realizar sus propias elecciones internas, un sector del FA decidiría votar en blanco en las elecciones internas de los otros partidos. La otra opción era el voto útil, es decir, que el voto de los frenteamplistas se diera a los sectores más progresistas de los partidos tradicionales.

El voto en blanco fue impulsado, en un principio, por el Partido Demócrata Cristiano -PDC- (que en ese momento se había desligado del FA), a través de la revista Opción y, posteriormente, por el líder de la coalición, Líber Seregni. ${ }^{11}$ El 19 de octubre se constituiría la Comisión Nacional de Ciudadanos por el Voto en Blanco.

En cuanto al voto útil, éste fue propiciado, sobre todo en el exterior del país, por la CDU, que proponía votar por los sectores más progresistas de los partidos tradicionales: ACF, dentro del Partido Nacional, o por los suble-

${ }^{11}$ Dado el papel fundamental del general Líber Seregni en la estrategia política del Frente Amplio en la transición a la democracia, vale la pena hacer una breve reseña de su trayectoria. Militar de carrera, Seregni obtuvo por concurso el grado de general en 1963 y tuvo bajo sus ordenes las regiones militares 1 y 2 . En 1969 se retiró del ejército. En 1971, junto a diversos partidos y organizaciones políticas, fundó el Frente Amplio. Desde entonces se convirtió en el líder de la coalición de izquierda. Ese año fue postulado como candidato a la presidencia de la República. Como ya se mencionó, en 1973 se produjo su primera detención durante la manifestación del 9 de julio contra el golpe de Estado. Posteriormente fue liberado y nuevamente preso en 1976; permaneció ocho años en prisión. Fue expulsado del ejército y considerado traidor a esa institución. Como veremos, desde la cárcel mantuvo su papel dirigente del FA. 
mas liderados por Sanguinetti y Tarigo, dentro del Partido Colorado.

El general Seregni, desde la cárcel, mandaba cartas a los frenteamplistas para guiarlos en las elecciones internas. En su primera carta decía que el Partido Nacional no necesitaba el apoyo del FA, pues eran mayoritarios los sectores progresistas en el interior de ese lema. De los colorados decía que no eran claras sus posiciones con respecto al gobierno militar y que, por tanto, no concitaban el apoyo de la coalición.

Esto último es importante. En 1982, la alianza más fuerte se daba entre blancos y frenteamplistas (sobre todo a través de la CDU). Si bien el FA había sido el sector más golpeado por la dictadura, el Partido Nacional también tenía muertos y, sobre todo, tenía a su máximo líder, Wilson Ferreira Aldunate, en el exilio. En cambio el Partido Colorado, donde había sectores que habían colaborado directamente con los militares y donde sus sectores más "progresistas" no sufrían el exilio, durante toda la transición había asumido la posición más dialoguista de todos los partidos.

Sin embargo, si el FA quería demostrar a los militares que era un actor importante en el sistema político, y reconstruir su identidad política, debía votar de manera independiente: el voto en blanco era su opción. En ese sentido, para Líber Seregni era necesario que la población uruguaya, tras diez años de dictadura, supiera que el FA estaba vivo y que estaba dispuesto a continuar la lucha.

Se puede decir que, por lo menos de manera formal, fue sobre todo a principios de 1982 cuando el Fa se dividiría en las dos posiciones. Conforme las elecciones se acercaban, sus dirigentes tanto en el exterior como en el país, se plegarían a la formulación de Seregni. Pero fue probablemente esa primera indefinición la que no permitió que la mayoría de los frenteamplistas asumiera como suya la posición del voto en blanco. Aunque también hay que tomar en cuenta la falta de medios de comunicación para que el Fa se acercara a la población.

Para Seregni, el voto de 1982 no se refería tanto a las elecciones en sí, sino a sus implicaciones políticas para el resto de la transición. Sabía que el Fa sólo podría participar en las negociaciones si demostraba a los militares y a los otros actores políticos su fortaleza. Así, durante la transición, el FA se estaba jugando su identidad política, su capacidad de permanecer como actor innegable en la arena política.

Pero si bien el FA participó en las negociaciones de 1984 , no fue gracias al voto en blanco de 1982. Por el contrario, los votos que dio al Partido Nacional tornaron a éste en un fuerte competidor que utilizaba el discurso más "radical" en contra de la dictadura. El aliado de coalición del FA se fortalecía y buscaba su propia independencia.

Vale la pena mencionar que los frenteamplistas no sólo aportaron votos a los partidos tradicionales sin obtener un apoyo de su parte; lograron así que sobre ellos recayeran las acusaciones de infiltración comunista.

Así, 1982 fue el primer año, dentro de la transición, en que el FA únicamente se manifestó de manera política 
ante la ciudadanía. Pero si bien se vio debilitado por su doble posición -voto en blanco, voto útil- en las elecciones internas, de cualquier manera había dejado sentadas las bases de que, como actor político, aún continuaba con vida.

\section{3: FORTALECIMIENTO FRENTEAMPLISTA}

El 13 de mayo de 1983 comenzó el diálogo entre militares y políticos en el Parque Hotel. El objetivo principal era discutir las reformas a la Constitución de 1967. Los militares pretendían consagrar una pseudodemocracia, en la cual ellos pudieran, de varias formas, seguir interviniendo.

$Y$ aunque, aparentemente, las FFAA querían dialogar, al mismo tiempo clausuraban semanarios (por ejemplo, de La Democracia, 24 números) y detenían políticos. Frente a esta situación, el ex presbítero Posadas, asistente al diálogo por parte del Partido Nacional, anunciaría que su partido podía abandonar éste si los militares insistían en su posición. Sin embargo, unos días después el Directorio nacionalista decidió continuar las pláticas con los militares, aunque criticando la actuación del gobierno. No obstante, los participantes del Partido Nacional fueron cambiados, pues los que habían acudido anteriormente se negaron a seguir participando en las conversaciones ante la actitud de los militares.

El 5 de julio se realizó la séptima y última sesión en el Parque Hotel. Los representantes de los partidos propusieron la interrupción o la suspensión del diálogo, debido a que consideraban la negociación estancada y, por otro lado, por la idea de que la suma de los diversos actos realizados por las autoridades era incompatible con el carácter del periodo de "transición" que se vivía.

En esas conversaciones los militares no estaban dispuestos a ceder en sus posiciones. Es probable que las fuerzas reales de los partidos políticos y de las FFAA aún no fueran similares. Es decir, los militares perdían fuerza, pero aún conservaban la suficiente para poder ser intransigentes.

Aun cuando el Fa no participó en las conversaciones del Parque Hotel, existe un punto importante respecto al tema que aquí se trata: ¿cómo vio estas conversaciones? En general se puede decir que existen dos opiniones al respecto: la primera que dice que no se tenía conocimiento de lo que en ellas sucedía; la segunda que dice que con mayor o menor detalle sí se conocía lo que ocurría. Sin embargo, existen más elementos para aceptar la segunda hipótesis. ${ }^{12}$

No obstante, lo más importante de 1983 , en cuanto a la actuación y reconstitución del Frente, no estuvo en el diálogo con los militares. Uno de los puntos decisivos fue el reagrupamiento de los movimientos sociales.

Entender la importancia del movimiento social y sindical de este periodo es imprescindible para comprender el papel del FA en la transición a la

${ }^{12}$ Sobre este punto, ver las entrevistas a José Pedro Cardozo, Líber Seregni y Juan Guillermo Young que se encuentran en Dutrénit, $\mathrm{Ma}$ remoto, 1994. 
democracia; pues, en un momento en que no era reconocido como actor válido por los otros actores políticos, y que estaba excluido de las conversaciones y de los medios masivos de comunicación, el Frente hizo suya nuevamente una antigua forma de acercamiento a la ciudadanía: la movilización social.

Aunque desde 1982 comenzó la reorganización tanto del Partido Blanco como del Colorado, se sabe que, por lo menos formalmente, el reacomodo de las fuerzas de la coalición de izquierda no se reinició sino hasta 1984.

Tanto la reconstitución de la fuerza de los partidos tradicionales como la liberalización por parte de los militares contribuyeron, de alguna manera, al resurgimiento de los movimientos sociales. Pero en el caso de la izquierda el proceso fue inverso: la fuerza de los movimientos sociales -donde se ubicaban los militantes de la izquierda partidaria-, presionó entre otras cosas a los partidos tradicionales y a los militares a reconocer al Frente como un actor político fundamental en la transición.

Durante 1983 se observó la proliferación de múltiples organizaciones y movimientos sociales. Por un lado, surgió la Federación Uruguaya de Cooperativas de Viviendas de Ayuda Mutua -FUCVAM-, que se conformó como un fuerte polo de oposición al régimen. También apareció la SERPAJ -Servicios de Paz y Justicia-, movimiento que se insertaba, sobre todo, en la corriente de la lucha por los derechos humanos. Por otra parte, las dos organizaciones más importantes eran nuevas sólo de nombre: primero la ASCEEP -Asociación Social y Cultural de Estudiantes de la Enseñanza Pública- que en realidad vino a remplazar a la vieja Federación de Estudiantes Universitarios de Uruguay (FEUU); segundo, el Plenario Intersindical de Trabajadores -PIT-, que remplazó a la CNT.

Fìnalmente, se creó la Intersectorial en agosto de ese año, organismo que agrupaba a todos los partidos políticos y a los distintos movimientos sociales. Era el primer intento por nuclear en un solo frente a toda la oposición a la dictadura, y resultaba muy importante porque era la primera vez que el fA participaba de manera formal junto a los demás partidos. En esa época se dieron los primeros acercamientos de los partidos tradicionales con el FA, sobre todo entre Sanguinetti y Seregni.

La Intersectorial convocó a un acto en el Obelisco, un importante monumento de Montevideo. El acto, conocido como el "obeliscazo", fue trascendental por varias razones. Primero, porque marcaba el punto más alto en la unidad de todos los partidos políticos-incluido el FA- en contra de la dictadura. Segundo, porque por primera vez la coalición de izquierda reaparecía en público, desde 1973 , y era reconocida como un actor válido por los otros partidos.

Fue la primera vez que los políticos de los partidos tradicionales compartían el estrado con la izquierda. De cada colectividad, había 25 representantes: 25 colorados, 25 blancos, 25 cívicos, 25 frenteamplistas y 25 demócratacristianos. Esto último porque, en ese momento, el PDC se había separado del FA, aunque nunca de manera formal, aduciendo que la coalición era inoperante bajo aquel contexto. Precisamente en este acto, la juventud demócrata- 


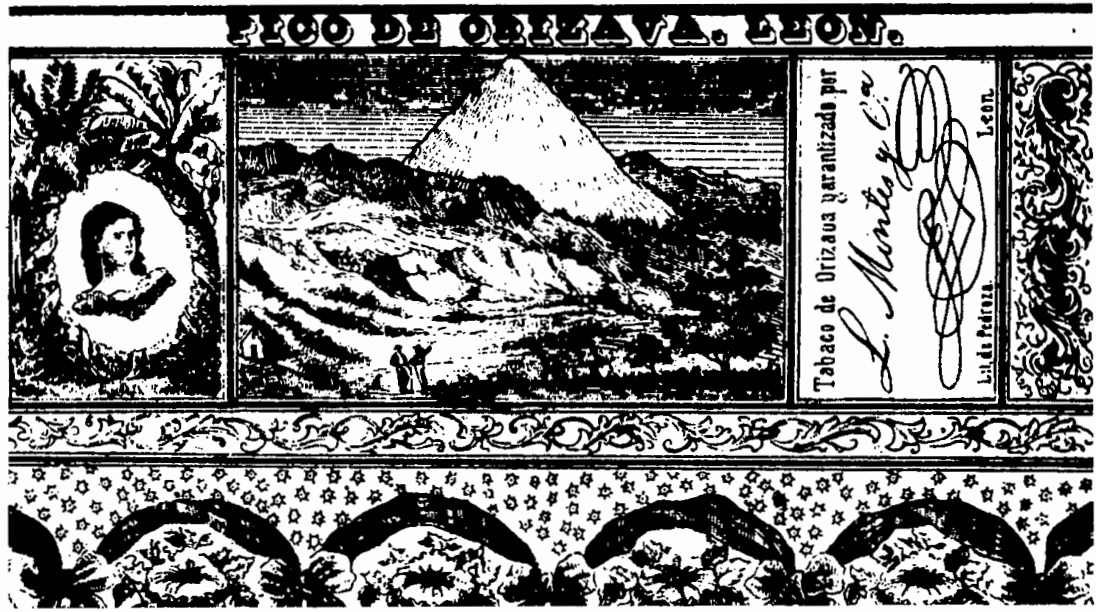

cristiana exigiría el retorno del PDC al Frente.

Este acto sería también sumamente importante en la transición a la democracia porque, por primera vez, los uruguayos, de cualquier militancia partidaria, decidieron retomar las calles. Los cálculos de asistencia presentan cifras que van de las 150 a las 400 mil personas. Sería, pues, parte del proceso de liberalización.

\section{4: PARTICIPACIÓN EN LA SALIDA PACTADA DE LA DICTADURA}

En 1984, igual que en los años anteriores de la transición, los militares buscaron una salida negociada con los partidos. Pero al mismo tiempo, continuaron aplicando la represión a los medios de comunicación y a la ciudadanía en general.
El 18 de enero de ese año, el prT convocó a un paro general. Fue el primero que se llevó adelante desde la huelga general de 1973, realizada por la CNT contra el golpe de Estado. Su éxito fue tal que el gobierno militar decidió la disolución del PIT. La acusación real contra ellos era que se estaban convirtiendo en la continuación de la CNT y que, por lo mismo, podrían llegar a convertirse en un polo de resistencia contra la dictadura.

Parte de la población intentó invertir las medidas tomadas por las FFAA, pero no contaron con el apoyo y la fuerza suficientes. Mientras tanto, los dirigentes de los partidos tradicionales no apoyaron al PIT, por lo que se disolvió la Intersectorial. Sin embargo, al mes siguiente ésta se reconformó, quedando integrada exclusivamente por sectores políticos y sindicales, aunque estos últimos sólo con voz y sin voto. 
Por su parte, el gobierno prohibió la ya limitada actividad política que existía, a la vez que la actividad sindical que, precariamente, se desarrollaba, y llevó el cercenamiento de la libertad de prensa a límites desconocidos.

El clima político parecía ponerse más enrarecido. Tras un tiempo en que se mostró marcado por la distensión -la liberación de Liber Seregni y de José Luis Massera, ${ }^{13}$ la reintegración de los cantautores Alfredo Zitarrosa (frenteamplista) y Daniel Viglietti y la reubicación en el Penal de Libertad de los llamados "presos rehenes"-, ${ }^{14}$ varios acontecimientos hicieron recordar que la dictadura continuaba en pie.

El más significativo de ellos fue la detención, tortura y asesinato de Vladimir Roslik. Roslik no era el primero en morir a consecuencia de la tortura en Uruguay, pero lo que realmente pareció exaltar el ánimo de la opinión pública -que realizó manifestaciones multitudinarias como rechazo-, fue que el mismo se llevara a cabo en el momento en que se buscaba establecer una negociación para lograr el fin del régimen militar.

Los medios, sobre todo los escritos, trataban de sacar a la luz la verdad acerca del asesinato, mientras el gobierno pretendía, de todas las formas posi-

${ }^{13}$ Matemático y dirigente comunista.

${ }^{14}$ En 1974, nueve dirigentes tupamaros fueron tomados como "rehenes", siendo sometidos a prisión aislada en distintos puntos del país bajo condiciones especialmente rigurosas. Los tupamaros "rehenes" fueron: Raúl Sendic, Eleuterio Fernández Huidrobo, Jorge Manera Lluveras, José Mújica Cordano, Jorge Zabalza Waksman, Julio Marenales Sáenz, Mauricio Rosencoff, Henry Engler y Adolfo Wassen Alainz. bles, acallarla: se realizaron clausuras $\mathrm{y}$ actos represivos a diversos medios y atentados anónimos perpetrados por grupos paramilitares.

No obstante, al mismo tiempo continuaban las conversaciones entre miembros de las FFAA y de los partidos políticos. Éstas no eran, en realidad, diálogos formales, sino encuentros entre militares y colorados, por una parte, y blancos y militares, por otra; el levantamiento de las proscripciones y la reforma constitucional -la institucionalización del Cosena- no permitían llegar a un acuerdo.

La posición de los colorados respecto a las primeras parecía ambigua. Mientras Enrique Tarigo ${ }^{15}$ afirmaba que se podría realizar la negociación con los militares con la proscripción vigente sobre Ferreira Aldunate y el Partido Comunista, Sanguinetti -junto con Humberto Ciganda, cívico- firmaba un recurso de babeas corpus reclamando la libertad de Seregni.

A esta petición se sumaron muchas otras, tanto nacionales como internacionales. El 19 de marzo, el general Seregni fue liberado. Las movilizaciones populares y el reconocimiento de Seregni por parte de los dirigentes de los partidos tradicionales como líder de la izquierda, modificaban la dinámica y el juego de los actores en el sistema político de la transición. Las declaraciones políticas de Seregni sorprendieron a todos los que esperaban que pusiera énfasis en la radicalización y en la confrontación directa con el régimen. Cambio. 
Frente a su casa improvisó un discurso en el cual manifestó que no debería existir "ni una sola consigna negativa". Dijo que estaba decidido a luchar desde el marco jurídico en que se encontraba, es decir proscripto. A partir de ese momento, Seregni comenzó una gran campaña para lograr la negociación con los militares.

El protagonismo del general logró reunificar al FA y devolverle su identidad política, debilitada hasta ese momento, así como consolidar una posición ante las negociaciones que hasta entonces no existía. Fue precisamente a iniciativa del líder de la coalición de izquierda que se reorganizó el frente de oposición a la dictadura a través de la Multipartidaria, antes Interpartidaria, que pasó a llamarse así una vez que entró a ella el FA.

Días después de la liberación de Líber Seregni, habían comenzado los acercamientos entre él y Sanguinetti. Quizá ya desde ese momento los colorados, con el doctor Sanguinetti a la cabeza, habían comenzado a percatarse de la importancia de contar con el $\mathrm{FA}$, para establecer las futuras negociaciones con las FFAA.

Sin embargo, algunos días antes de esos acercamientos se había interrumpido el diálogo entre colorados y blancos, al parecer por una propuesta que estos últimos habían hecho al gobierno, referente a una posible prolongación del mandato del general Álvarez. Las alianzas de los políticos se recomponían.

El FA, a través del eje "movilizaciónconcertación-negociación", exigía el establecimiento de condiciones pacíficas para iniciar la negociación y convo- caba a una mayor cohesión del frente opositor. Tras muchas pérdidas humanas y con militantes en la cárcel, después de los largos años de fuerte represión la izquierda entendía que la mejor posición a adoptar era la conciliación y la negociación con los militares. Tal y como Seregni lo diría:

Negociamos porque somos fuertes. De lo contrario, se nos impondrían las soluciones. Pero también negociamos porque el enemigo es fuerte, y porque no somos capaces de imponerle nuestras soluciones. ${ }^{16}$

Por su lado, el Partido Nacional planteó una iniciativa en pro de organizar un plebiscito para la derogación de los A 4 y $7 .{ }^{17} \mathrm{Su}$ iniciativa no fue secundada por los demás partidos políticos. A partir de eso, el distanciamiento entre el Partido Blanco y el resto del espectro partidario comenzó a volverse infranqueable. El Consejo de Estado, a pesar de que los nacionalistas juntaron las 600000 firmas necesarias, les negó la solicitud. Éstos se radicalizaban, mientras la posición del fa se volvía más negociadora y se aliaba al Partido Colorado que mantenía una postura conciliadora.

El primero de mayo los militares entregarían a los dirigentes de los partidos tradicionales un documento con

${ }^{16}$ Aguirre Bayley, Frente, 1985, p. 66.

${ }^{17}$ Recordemos que el Av4 declaró proscritos -prohibiéndoseles, por el término de quince años, la actividad política- a los ciudadanos que hubiesen sido candidatos a cargos nacionales, departamentales o locales en las elecciones de 1966 y 1971 . Por su parte, el AI7 hacía referencia a la movilidad de los funcionarios públicos. 
las "bases de acuerdo" para las negociaciones. ${ }^{18}$ El 22 de mayo, en un documento conjunto, los partidos declararon: que actuarían de manera concertada, que las elecciones del 25 de noviembre tenían que ser sin proscripciones y que cualquier modificación a la constitución debía ser plebiscitada.

Pese a esta declaración, las posiciones de todos los partidos no eran similares. Colorados y cívicos decían que ya se podía realizar una negociación con los militares. Los blancos argumentaban que el documento era inaceptable en su totalidad y los frenteamplistas, que había puntos inaceptables, pero que en general se podía aceptar.

El 4 de junio, los comandantes de las tres FFAA se reunieron con los dirigentes de los partidos habilitados para comunicarles la ratificación del cronograma, ${ }^{19}$ la prohibición de todo tipo de manifestación pública y la detención de Ferreira Aldunate tan pronto ingresara al país.

Y en lo que se consideró como el mayor reconocimiento a la existencia del FA y al liderazgo político del general Seregni, el general Rapela, ministro del Interior, le comunicó al líder de la izquierda las resoluciones del gobier-

${ }^{18}$ En estas bases los militares manifestaban sus intereses con respecto a trece puntos. De hecho, proponian mantener una serie de medidas autoritarias contra la población, violando los derechos humanos de la sociedad, en puntos tales como mantener en vigencia el AI4, que se mantuviera el COSENA, entre otros.

${ }^{19}$ El cronograma de los militares proponía elecciones generales el 25 de noviembre de 1984 , así como que ese mismo dia se eligiera una asamblea general que tendría carácter constituyente entre el 1 de julio y el 31 de octubre de 1985. no. Rapela afirmaría que Seregni era informado debido a su participación en la Multipartidaria. Por su parte, Seregni aseguró que había sido enterado de la decisión de los militares de levantar la proscripción a algunos partidos del FA dado que se había llegado a un acuerdo entre las FFAA y los políticos. Más allá de lo dicho por Rapela, este hecho implicaba el reconocimiento del Frente Amplio como un actor indispensable en la escena política, así como el entendimiento de una necesidad: que no estando el PN dispuesto a negociar, se debía incluir un interlocutor nuevo y válido. Aunque no todos los militares pensaban igual a este respecto.

Mientras tanto, el 16 de junio Wilson Ferreira intentaría regresar al país en barco desde Argentina. Antes de llegar al puerto, él y su hijo, Juan Raúl Ferreira, fueron detenidos, y posteriormente enjuiciados y encarcelados por los militares. Inmediatamente se comenzó a reclamar la libertad de ambos políticos. Al mismo tiempo, el Partido Nacional asumió la posición de no negociar con los militares mientras aquéllos estuvieran presos.

El 25 de junio, los partidos emitieron una declaración en la cual confirmaban su decisión de dialogar con los militares; en tanto, los nacionalistas se separaron del resto de los partidos. Esto llevó a un enfrentamiento entre el FA y el PN, dado que éstos consideraban que el FA estaba modificando su posición de una manera extrema.

El 6 de julio se reiniciaron las con. versaciones político-militares. Por parte de los partidos asistieron Sanguinetti, Tarigo y Jorge Batlle -colorados-, Juan Vicente Chiarino y Humberto Ciganda 
-cívicos- y José Pedro Cardozo y Juan Guillermo Young -frenteamplistas-; el PN había decidido que no asistiría a las negociaciones mientras Wilson Ferreira estuviera preso.

Este diálogo significó, entre muchas otras cosas, la reaparición definitiva del FA en el escenario político del país, en tanto que el FA comenzaba su reagrupación y el PDC afirmaba su respaldo total a los delegados frenteamplistas encargados del diálogo con las FFAA. Se debe tomar en cuenta que Juan Guillermo Young, representante del FA ante los militares, era demócratacristiano. $Y$ que este regreso del PDC al FA se había dado sólo tras la renuncia del líder del PDC, Juan Pablo Terra. Entonces, no sin fuertes convulsiones, el FA recuperaría su identidad política, incluso con más fuerza que en 1971. Y esto se debió, en gran medida, al liderazgo de Líber Seregni y, también, a la estrategia de movilización-concertación-negociación.

Mientras tanto, los militares aceptaron levantar la proscripción al PDC, lo que permitiría al FA concurrir a las elecciones bajo ese lema pero excluidos de él el Partido Comunista y Líber Seregni, dado que, efectivamente, el 26 de julio los militares levantaron la proscripción sólo a partes del FA.

Sin embargo las FFAA comenzaban a ceder cada vez más. Parecía que tanto ellas como los políticos se percataban de que la única forma de encontrar una salida era a través de conceder ambos en diversos aspectos. El 3 de agosto se realizó la última reunión del Club $\mathrm{Na}$ val. Las bases de lo acordado se encuentran en el AI19, que previó un conjunto de normas constitucionales transito- rias: que el COSENA se convirtiera en órgano de asesoría del poder ejecutivo en materia de seguridad nacional; que el estado de insurrección pudiera aplicarse en los casos o hechos graves que atentaran contra el orden público o la seguridad nacional; con respecto a la jurisdicción militar, ésta se extendería a los delitos militares establecidos por la ley, los de lesa nación, que eran aquellos utilizados como medios de acción de la subversión o, en el caso de estado de guerra, cometidos por civiles o militares. Asimismo, se confirmaría que la asamblea general, que se elegiría el 25 de noviembre, tendría carácter constituyente entre el 1 de julio y el 31 de octubre de 1985.

Este modelo de salida no puede ser considerado como exclusivo de un actor específico. En realidad fue el modelo que más convino a todos los actores en este caso -excepto a los del PN que, sin embargo, tuvieron que modificar sus posiciones por la actuación de los demás.

Los militares aceptaron en 1985 que las reformas constitucionales se plebiscitaran. Pero mantuvieron una posición de fuerza con respecto a Wilson Ferreira Aldunate. Temían que éste pudiese ganar las elecciones y enjuiciarlos. Quizá por eso tampoco anularon la exclusión de Líber Seregni, para que a la vista de todos su actitud con Ferreira pareciese más "justa", además de que así se desactivaba también la candidatura del general.

El Partido Nacional, por su lado, no cedió en el tema de la liberación de su líder, Ferreira Aldunate, y buscó la alianza con el FA, sobre todo con respecto al tema de las proscripciones, sin lograr- 
lo. Su carta fuerte era pensar que el FA debía unirse a ellos (por cuestiones políticas históricas) y no a los colorados. La posición del PN fue la más radical de todos los partidos.

El Partido Colorado fue, quizá, el actor triunfante en este modelo de salida. Si bien no contó con el PN, se acercó al FA, como última opción, para poder negociar con los militares. Habría que recordar el momento en que, en Bolivia, Sanguinetti le dijo a Ferreira que ellos negociarían con los militares, y que si el PN no lo hacía, buscarían el apoyo de los frenteamplistas. ${ }^{20} \mathrm{La}$ posición de los colorados fue la más negociadora de todos los partidos. Y fue esto, en gran medida, lo que les permitió ganar las elecciones de 1984, ya que la población estaba interesada en apoyar a los partidos y sectores capaces de establecer las medidas más concertantes, aquellas que evitaron una posible nueva injerencia de los militares en el gobierno.

El FA, por su parte, tuvo, durante el último año de la transición, una posición intermedia entre los blancos y los colorados. Dejaron de lado la lucha por levantar las proscripciones y por el movimiento social para recuperar antes su identidad política y su caudal electoral. Pero es necesario decir que en todos los actores partidarios pesaron los factores electorales, aunque de distinta manera. El FA tenía que elegir entre una posición de lucha frontal contra la dictadura y una posición conciliadora que le permitiese negociar para salir de ella y tener un buen desempeño

${ }^{20}$ Ver Achard, Transición, 1989, p. 54. electoral (finalmente, en Uruguay sólo se es un actor político importante si se consigue una votación favorable). Así, optó por la última.

Recapitulando, se podría decir que quizá lo más importante en 1984 fue que el llamado "cáncer de la sociedad" -es decir, la izquierda- asistió al Pacto del Club Naval, que fue así avalado por todos los actores políticos -excepto por el Partido Nacional-, concurrió a las elecciones e, incluso, fue el único en incrementar su caudal electoral. Pero no debe omitirse que fue el centro del espectro político reunido en el Fa el que triunfó, así como fue el centrismo en general el que triunfó a nivel nacional.

\section{Algunas CONCLUSIONES}

Debemos tener en cuenta que, en el modelo de salida de la dictadura en Uruguay, existen elementos atípicos con respecto a otros casos de transiciones a la democracia, como por ejemplo el argentino y el chileno: 1) los partidos políticos no van unidos a negociar, en este caso con los militares; 2) la izquierda partidaria es parte de la negociación; 3) la oposición más fuerte provino de uno de los partidos tradicionales y no de la izquierda, y 4) el movimiento social es marginado de las fuerzas de oposición y, sobre todo, marginado por la propia izquierda en su búsqueda de un papel negociador.

La transición a la democracia en Uruguay fue una de las pocas, en América Latina, que se basó en un acuerdo explícito entre los militares y parte de la oposición unificada contra ellos. A 


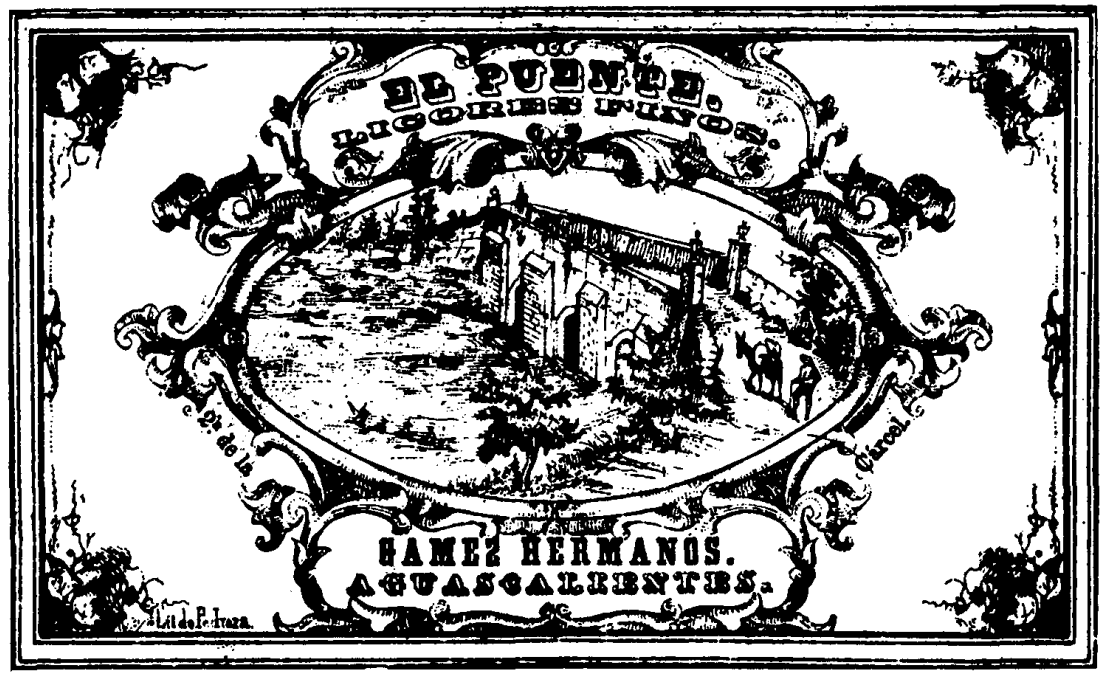

las negociaciones, lo hemos visto ya, sólo asistieron el Partido Colorado, la Unión Cívica y el Frente Amplio; el Partido Nacional se automarginó por las condiciones imperantes. Pero, además, el Frente Amplio es la única organización de izquierda en América Latina que negoció directamente con los militares. El propósito de las FFAA al tomar el gobierno, en todas las dictaduras del Cono Sur, era acabar con la izquierda, fuese partidaria o no, marxista o no, tuviera nexos internacionales o no; la meta era exterminarla, porque, pensaban los militares, ella era la responsable del caos nacional. Entonces, el hecho de que el Frente Amplio haya participado en el Pacto del Club Naval es insólito en el contexto latinoamericano. Pero es importante dejar claro que, si los militares uruguayos lo per- mitieron, no fue porque estuvieran a favor de la coalición de izquierda, sino porque lo requerían para obtener la salida negociada. Las FFAA sabían que no podían hacer un pacto exclusivamente con el Partido Colorado ${ }^{21}$ y, como no estaban dispuestos a ceder ante las demandas del Partido Nacional, ante el imperativo de que debían alejarse del gobierno tuvieron que recurrir al Frente Amplio, que sí estaba dispuesto a negociar.

En este sentido, vale la pena rescatar la tradición de pactismo que ha existido en la vida política uruguaya

${ }^{21}$ También estaba la Unión Cívica, pero era un partido con poca relevancia cualitativa y cuantitativa. Los militares no contaban con este partido como elemento importante en la negociación. 
desde el siglo xIx, con lo cual se puede decir que la dictadura militar la respetó en muchos aspectos o, por lo menos, que no logró evadir los patrones clásicos de comportamiento político existentes en el país.

De esa manera, hemos visto que el papel del Frente Amplio, de la izquierda uruguaya, fue fundamental en la primera parte de la transición a la democracia en Uruguay, aquella que fue de 1980 a 1984 (todavía bajo el gobierno militar). Y que si bien su papel también fue importante de 1985 a 1989 (año en que se da el plebiscito sobre la Ley de Caducidad de la Pretensión Punitiva del Estado, ${ }^{22}$ con el cual termina la transición), hemos considerado importante recorrer sólo el primer momento porque, definitivamente, podemos hacer una diferenciación entre el Frente Amplio de la transición en el go-

${ }^{22}$ En 1986, el Parlamento uruguayo ratificó esta ley, que significó poner un punto final a la posibilidad de juzgar a los militares por las violaciones de los derechos humanos realizadas durante la dictadura. A partir de este hecho, una serie de ciudadanos y organizaciones políticas decidieron conseguir las firmas necesarias para convocar a un plebiscito sobre la ley. Fueron conseguidas en 1989 y ese mismo año se llevó a cabo el plebiscito, que dio como resultado la ratificación de la ley por la ciudadanía. Para muchos estudiosos del tema, con el plebiscito sobre esta ley, realizado en 1989 , se termina la transición a la democracia, pues este tema (la violación de los derechos humanos durante la dictadura) era el último que quedaba pendiente del régimen anterior. La votación a favor de la ley podría interpretarse más como un reflejo del "voto del miedo" que como una aprobación de lo actuado por los militares durante la dictadura. bierno militar y el de la transición en el gobierno civil.

En esta primera etapa el Frente Amplio se ve favorecido por las condiciones históricas imperantes y decide aceptar el reto de participar en la negociación. Parecería que la mayoría de sus militantes, así como la ciudadanía, habrían respaldado esa decisión, tal como se puede apreciar en las elecciones nacionales de 1984 y de 1989 , en donde el Fa no sólo amplía su caudal electoral, sino que accede en 1989 , por primera vez, a la intendencia de Montevideo.

De tal forma, casi podríamos decir que debemos estar de acuerdo con los autores que han planteado que en las transiciones se requieren actores moderados, ${ }^{23}$ en lugar de "radicales" (sin importar la orientación que tengan, ya sea de izquierda o de derecha). En el caso uruguayo, quienes fueron ratificados posteriormente por la ciudadanía fueron los actores de centro (o que se colocaron en el centro del espectro político en ese momento): el Partido Colorado y el Frente Amplio. La izquierda uruguaya debió moderarse para ser parte del pacto de la transición negociada en Uruguay, y de la misma manera podríamos entender el resultado del plebiscito de 1989 sobre la Ley de Caducidad: los actores moderados serían los que tuvieron más apoyo en estos procesos de transición a la democracia.

${ }^{23}$ Gillespie, Negotiating, 1991; O'Donnell, Transiciones, 1988. 


\section{Hemerografía}

-Búsqueda, algunos números entre 1982 y 1985, Montevideo.

-Correo de los Viernes, 1982, Montevideo.

-Desde Uruguay, enero-junio de 1982, Montevideo.

Jaque: Revista Semanario, 1984-1985, Montevideo.

-La Democracia, 1982-1985, Montevideo.

-Opinar: Revista Semanario, 1982-1985, Montevideo.

\section{BIBLIOGRAFÍA}

-Achard, Diego, La transición en Uruguay, Instituto Wilson Ferreira Aldunate, Montevideo, 1989.

-Aguirre Bayley, Miguel, El Frente Am. plio. Historia y documentos, Ediciones de la Banda Oriental, Montevideo, 1985.

-Caetano, Gerardo y José Rilla, Breve bistoria de la dictadura, EBO-Centro Latinoamericano de Economía Humana, Montevideo, 1989.

-Caetano, Gerardo , et al., De la tradición a la crisis. Pasado y presente de nuestro sistema de partidos, EBO-CLAEH, Montevideo, 1991.

-Castagnola, José Luis y Pablo Mieres, La ideologia política de la dictadura, ЕBO, Montevideo, 1988.

-Convergencia Democrática en Uruguay. Documentos políticos. La CDU es una experiencia unitaria, Ediciones CDU, México, 1984.
-Dutrénit Bielous, Silvia, El maremoto militar y el arcbipiélago partidario. Testimonios para una bistoria reciente de los partidos políticos, Instituto de Investigaciones Dr. José María Luis Mora/Ediciones de Ciencias Sociales, Montevideo, 1994. "Los partidos políticos durante la dictadura. (Un enfoque histórico de sus actos entre 1973 y 1984)", tesis de doctorado, CPYS-UNAM, México, 1994.

-Gillespie, Charles, Negotiating democracy. Politicians and generals in Uru. guay, Cambridge Latin American Studies, Cambridge, 1991.

-González, Luis E., Estructuras politicas $y$ democracia en Uruguay, Fundación de Cultura Universitaria Instituto de Ciencia Política, Montevideo, 1993.

-Harnecker, Martha, Los desafíos de una izquierda legal, La República, La Habana, 1991, 4 tomos.

-O'Donnell, Guillermo et al., Transiciones desde un gobierno autoritario, Paidós, Buenos Aires, 1988, 4 tomos.

-Puchet Anyul, Martín, "Elecciones, cam. bios políticos y nuevos gobiernos en Uruguay", Secuencia, Nueva Época, Instituto Mora, núm. 18, septiembre-diciembre de 1990, México, pp. 203-228.

-Sierra, Gerónimo de, "La izquierda en la transición", Revista Mexicana de Sociologia, Instituto de Investigaciones SocialesUNAM, año XIVII, núm. 2, abril-junio de 1985, México.

Zubillaga, Carlos, "Los partidos políticos ante la crisis" en Caetano, Tradición, 1991, pp. 41-112. 